\title{
Atorvastatin was at least as effective as PTCA for reducing ischaemic events in patients with stable coronary artery disease
}

Pitt B, Waters D, Brown WVet al for the Atorvastatin versus Revascularization Treatment Investigators. Aggressive lipid-lowering therapy compared with angioplasty in stable coronary artery disease. N Engl J Med 1999 Jul 8;341:70-6.

QUESTION: In patients with stable coronary artery disease (CAD), is atorvastatin as effective as percutaneous transluminal coronary angioplasty (PTCA) plus usual care for reducing ischaemic events?

Design

Randomised, blinded (outcome assessors),* controlled trial with 18 months follow-up.

Setting

37 clinical centres in North America and Europe.

\section{Patients}

341 patients (mean age 59 y, 85\% men, 95\% white) recommended for PTCA who had stable CAD and asymptomatic or Canadian Cardiovascular Society class I or II angina, low-density lipoprotein (LDL) cholesterol level $\geq 3.0 \mathrm{mmol} / \mathrm{l}(115 \mathrm{mg} / \mathrm{dl})$, triglyceride level $\leqslant 5.6$ $\mathrm{mmol} / \mathrm{l}(500 \mathrm{mg} / \mathrm{dl})$, and stenosis $\geq 50 \%$ in $\geq 1$ coronary artery. Exclusion criteria were left main CAD, triple-vessel disease, ejection fraction $<40 \%$, or recent unstable angina or myocardial infarction (MI). Follow-up was $100 \%$.

\section{Intervention}

164 patients were allocated to atorvastatin, $80 \mathrm{mg} /$ day, and were required to stop other lipid-lowering treatments. 177 patients were allocated to PTCA and usual care, which could include lipid-lowering drugs.

\section{Main outcome measures}

Ischaemic events (death from cardiac causes, resuscitation after cardiac arrest, non-fatal MI, coronary artery bypass grafting, cerebrovascular accident, angioplasty, or worsening angina that required admission to hospital).

Source of funding:

Parke-Davis

Pharmaceutical

Research.

For correspondence:

Dr B Pitt, Division of

Cardiology, University

of Michigan Medical

Center, 3910 Taubman,

1500 East Medical

Center Drive, Ann

Arbor, $M I$

48109-0366, USA

FAX 734-936-5256.

\section{Main results}

All patients were included in the intention-to-treat analysis. Survival analysis showed that patients in the atorvastatin group had a reduced rate of ischaemic events $(p=0.048$, which was not statistically significant after adjustment for interim analysis) (table), a longer time to first ischaemic event ( $p=0.03)$, but less improvement in angina scores $(p=0.009)$ than did patients in the PTCA group. Patients in the atorvastatin group also had lower levels of LDL cholesterol $(2 \mathrm{mmol} / \mathrm{l}$ [77 $\mathrm{mg} / \mathrm{dl}]$ v $3 \mathrm{mmol} / \mathrm{l}[119 \mathrm{mg} / \mathrm{dl}], \mathrm{p}<0.05)$, total cholesterol, and triglycerides $(\mathrm{p}<0.05)$. The groups did not differ for quality of life or adverse events.

Atorvastatin v percutaneous transluminal coronary angioplasty (PTCA) plus usual care for patients with stable coronary artery diseaset

\begin{tabular}{|c|c|c|c|c|}
\hline $\begin{array}{l}\text { Outcome at } \\
18 \text { months }\end{array}$ & Atorvastatin & PTCA & RRR $(95 \%$ Cl) & NNT (CI) \\
\hline Any ischaemic event & $13.4 \%$ & $20.1 \%$ & $35.8 \%(-3$ to 60$)$ & Not significant \\
\hline
\end{tabular}

\section{COMMENTARY}

PTCA is widely used in patients with stable angina. Several studies comparing PTCA with medical therapy in patients with stable CAD showed an improvement in angina in the PTCA group but no reduction (and in some cases an increase) in ischaemic events. Abundant evidence suggests that stabilisation of vulnerable plaque with statins reduces ischaemic events and that MIs are more likely to arise from mild and moderate stenoses than from the severe stenoses targeted for PTCA. Until now, no study has included aggressive lowering of LDL cholesterol levels in patients randomly assigned to medical therapy, and for this, the Atorvastatin $v$ Revascularization Treatment (AVERT) investigators are to be congratulated.

The study was limited because the patient sample was at relatively low risk for ischaemic events, the sample size was small, stents were used less than in contemporary practice, a cost-effectiveness evaluation was not done, and lowering of LDL cholesterol levels was not applied equally to both groups. This latter point is important for 2 reasons. Firstly, patients in the PTCA group did not usually meet the US National Cholesterol Education Program target of an LDL cholesterol level $<2.6 \mathrm{mmol} / \mathrm{l}(100 \mathrm{mg} / \mathrm{dl})$. Secondly, we must understand exactly what PTCA offers patients with stable CAD-relief of angina but not necessarily the decrease in ischaemic events or mortality that cholesterol level-lowering drugs have shown. If lowering of LDL cholesterol levels were equal in both groups, it would be possible to isolate the incremental value of PTCA.

Hence, the AVERT trial ushers in a new era, reassuring us that medical therapy is a reasonable, safe, and perhaps preferable initial strategy for low-risk patients with stable CAD. The trial blazes the path for a larger study that is powered to look at hard end points and includes higher-risk patients and in which the PTCA group receives the same risk-factor reduction as the medical group. The optimal treatment for all but very high-risk patients with $\mathrm{CAD}$ is possibly a combination of PTCA and aggressive risk reduction, which would give such patients the best of both worlds: better relief of symptoms with PTCA and slower progression of atherosclerosis with risk-factor control.

David J Maron, MD Vanderbilt University School of Medicine Nashville, Tennessee, USA 